\title{
Chronic mandibular osteomyelitis with suspected underlying synovitis, acne, pustulosis, hyperostosis, and osteitis (SAPHO) syndrome: a case report
}

This article was published in the following Dove Press journal:

Journal of Inflammation Research

24 February 2012

Number of times this article has been viewed

\section{Yumi Mochizuki \\ Ken Omura \\ Hideaki Hirai \\ Takuma Kugimoto \\ Toshimitu Osako \\ Takahide Taguchi}

Department of Oral and Maxillofacial Surgery, Oral Restitution, Division of Oral Health Sciences, Graduate School of Medical and Dental Sciences, Tokyo Medical and Dental University, Tokyo, Japan
Correspondence:Yumi Mochizuki Oral and Maxillofacial Surgery,

Department of Oral Restitution, Division of Oral Health Sciences, Graduate School, Tokyo Medical and Dental University, I-5-45 Yushima, Bunkyo-ku, Tokyo I I3-8549, Japan

Tel +81358035506

$\mathrm{Fax}+81358030199$

Email mochizuki.osur@tmd.ac.jp

\begin{abstract}
Chronic mandibular osteomyelitis is an intractable disease. In recent years, some case reports have related this disease process to synovitis, acne, pustulosis, hyperostosis, and osteitis (SAPHO) syndrome, which is chronic with frequent remissions and exacerbations. This report describes a case of chronic mandibular osteomyelitis suspected to be SAPHO syndrome. A 68-year-old woman presented with pain on the left side of the mandible. On the basis of clinical and radiological findings, chronic mandibular diffuse sclerosing osteomyelitis was initially diagnosed. We administrated oral clarithromycin (400 mg daily) and levofloxacin (500 mg daily), and her pain subsequently resolved. On ${ }^{99 \mathrm{~m}} \mathrm{Tc}$-labeled methylene diphosphonate scintigraphy, tracer uptake in the asymptomatic mandible was unchanged, but there was increasing tracer uptake in the sternocostal and sternoclavicular joints, compared with ${ }^{99 \mathrm{~m} T c-l a b e l e d ~ m e t h y l e n e ~}$ diphosphonate scintigraphic findings of the first visit. We diagnosed SAPHO syndrome and administrated oral sodium risedronate hydrate ( $2.5 \mathrm{mg}$ daily). Although there has been no pain or swelling in the area of the left mandibular lesion, we have followed up on other skin and osteoarticular manifestations in conjunction with other medical departments.
\end{abstract}

Keywords: SAPHO syndrome, diffuse sclerosing osteomyelitis, 14-membered ring macrolide antibiotics, new quinolone antibiotics, bisphosphonates

\section{Introduction}

Synovitis, acne, pustulosis, hyperostosis, and osteitis (SAPHO) syndrome is a disorder characterized by pustular skin lesions and osteoarticular lesions proposed in 1987 by Chamot et al. ${ }^{1}$ Hyperostosis refers to excessive osteogenesis, which is visualized radiographically as osteosclerosis. Typical skin lesions include palmoplantar pustulosis and severe acne (such as acne conglobata and acne fulminans), or hidradenitis suppurativa. ${ }^{1-4}$ A number of associations between skin conditions and osteoarticular disorders have been reported under a variety of names, including chronic recurrent multifocal osteomyelitis, sternocostoclavicular hyperostosis, pustulotic arthroosteitis, and acne-associated spondyloarthropathy. ${ }^{2,3,5}$

The SAPHO acronym was proposed to group these various disorders. ${ }^{1,6}$ SAPHO syndrome is not an independent ailment, but a combination of symptoms, ${ }^{7}$ as sometimes individual osteoarticular and skin manifestations appear asynchronously., Some studies have indicated recurrent osteomyelitis of the mandible in almost $10 \%$ of patients with SAPHO syndrome. ${ }^{1,6,10}$ We report here a case of diffuse sclerosing osteomyelitis of the mandible in which SAPHO syndrome was suspected, and we discuss clinicopathological characteristics of the disease based on a review of the literature. 


\section{Case}

A 68-year-old woman was admitted to our clinic in August 2010 with a 14-month history of pain in the left side of the mandible. One month after treatment of a chronic apical lesion of the mandibular left canine in October 2007, she developed pain in the left side of the mandible. Mandibular osteomyelitis was diagnosed by radiographic and laboratory findings at another hospital in May 2008. She had a history of anemia from 6 to 40 years of age. When she was 66 years old, psoriasis developed on her dorsal, palmar, and plantar skin.

There was no trismus or paresthesia of the left side of the lower lip and chin on her first visit to our clinic. Oral examination showed tooth loss from the left first premolar to the left third molar and no evidence of either mucosal or bone lesions. Panoramic radiography showed osteosclerosis from the left premolar to the mandibular ramus region (Figure 1). Computed tomography of the head and neck showed enlarged canals of the left mandible and increased density of cancellous bone, which seemed to be reactive bone remodeling (Figure 2). On magnetic resonance imaging, jaw lesions showed low signal intensity on $\mathrm{T}_{1}$-weighted images and heterogeneous intermediate-to-high signal intensity on fatsuppressed $\mathrm{T}_{2}$-weighted images (Figure 3). Bone scintigram ( ${ }^{99 \mathrm{~m}}$ Tc-labeled methylene diphosphonate) showed extremely intense tracer uptake in the left mandible, the sternum, and the sternocostal and sternoclavicular joints (Figure 4). Mandibular osteomyelitis was diagnosed at the first visit. Because pain had resolved, we followed up for 4 months. She reexperienced pain and trismus. We administrated oral loxoprofen
(60 mg daily) for 1 month, and the pain resolved. However, radiographic examination showed development of inflammation in the soft tissue around the left mandibular condyle and resorption of condylar bone (Figure 5). We empirically started clarithromycin (400 mg daily) and levofloxacin (500 mg daily). Six months later, scintigraphic examination showed almost the same level and range of uptake in the left mandible, and stronger and wider uptake in the sternum and the sternocostal sternoclavicular joints, compared with the findings obtained 1 year earlier (Figure 6). Laboratory data were in the normal range, except for platelets $(323,000$; normal range: 128,000-280,000/ $\mathrm{LL}), \mathrm{C}$-reactive protein (1.26 mg/dL; normal range: $<0.30 \mathrm{mg} / \mathrm{dL}), \mathrm{C} 3(321 \mathrm{mg} / \mathrm{dL}$; normal: $86-160 \mathrm{mg} / \mathrm{dL}), \mathrm{C} 4(60.3 \mathrm{mg} / \mathrm{dL}$; normal range: $17-45 \mathrm{mg} / \mathrm{dL}$ ), and alkaline phosphatase (386 U/L; normal range: 104-338 U/L). She was negative for rheumatoid factor. A presumptive diagnosis of SAPHO was made. After consultation with her physician, we prescribed oral risedronate hydrate (2.5 mg daily). The patient showed no mandibular symptoms 12 months after starting conservative therapy.

\section{Discussion \\ Etiology and pathogenesis}

The prevalence of SAPHO syndrome has been estimated to be probably no greater than one in 10,000 in Caucasians ${ }^{11}$ and to be 0.00144 in 100,000 in Japanese. ${ }^{12}$ Hayem et al ${ }^{6}$ reviewed 120 cases of SAPHO syndrome. They described female predominance with patients younger than 30 years at onset, anterior chest wall as the most commonly affected bone-lesion site, peripheral arthritis in one-third of patients,

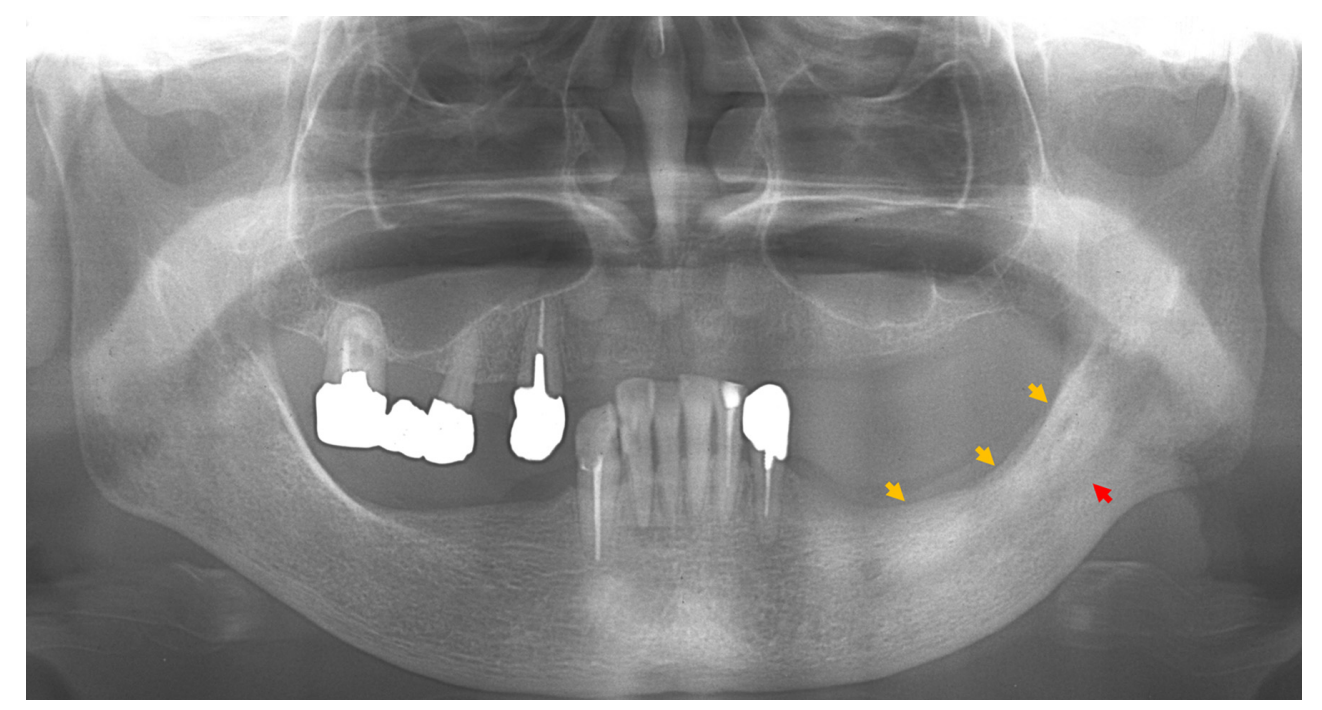

Figure I Panoramic radiograph at first visit, showing a ground-glass appearance (yellow arrows) from the left premolar to the mandibular ramus region and enlarged canals of the left mandible (red arrow). 


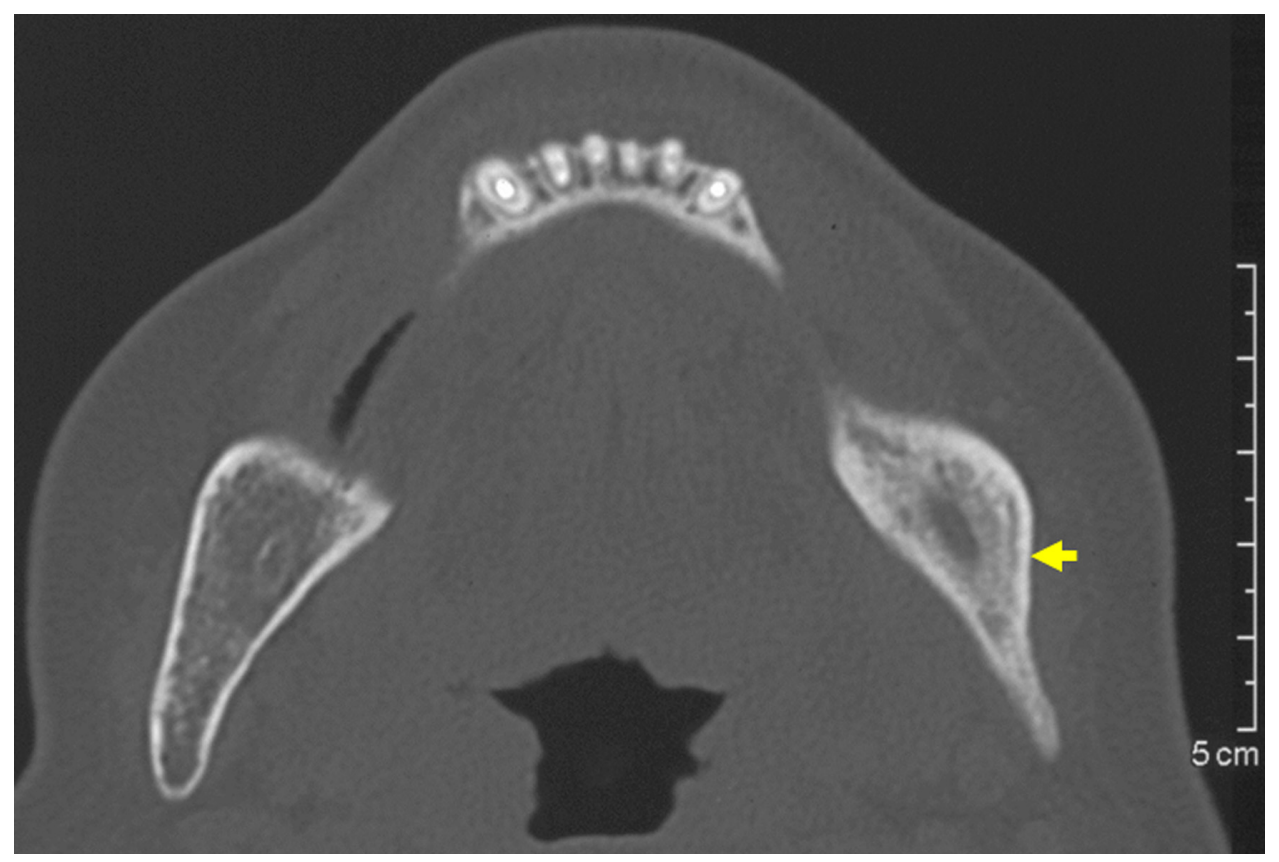

Figure 2 Plain computed tomography at first visit revealed increased density of cancellous bone.

and pustular dermatitis as a frequent complication. Yabe et $\mathrm{al}^{13}$ reported that most of the Japanese patients exhibited onset in middle age. In addition, differences between Caucasians and Japanese may be an influential factor.

The most common target site for bone lesions in adults is the anterior chest wall, in particular the clavicles, sternum, and sternoclavicular joints ( $70 \%-90 \%$ of patients), followed by the sacroiliac region ( $40 \%$ of patients), the spine (33\% of patients), the mandible (almost $10 \%$ of patients), and the pubic symphysis (7\% of patients). ${ }^{6,8,11,14}$

Adequate data on the prevalence of this syndrome are unavailable because of diverse clinical manifestations and lack of validated classification or diagnostic criteria. Preliminary criteria need improvement and further validation. ${ }^{15}$

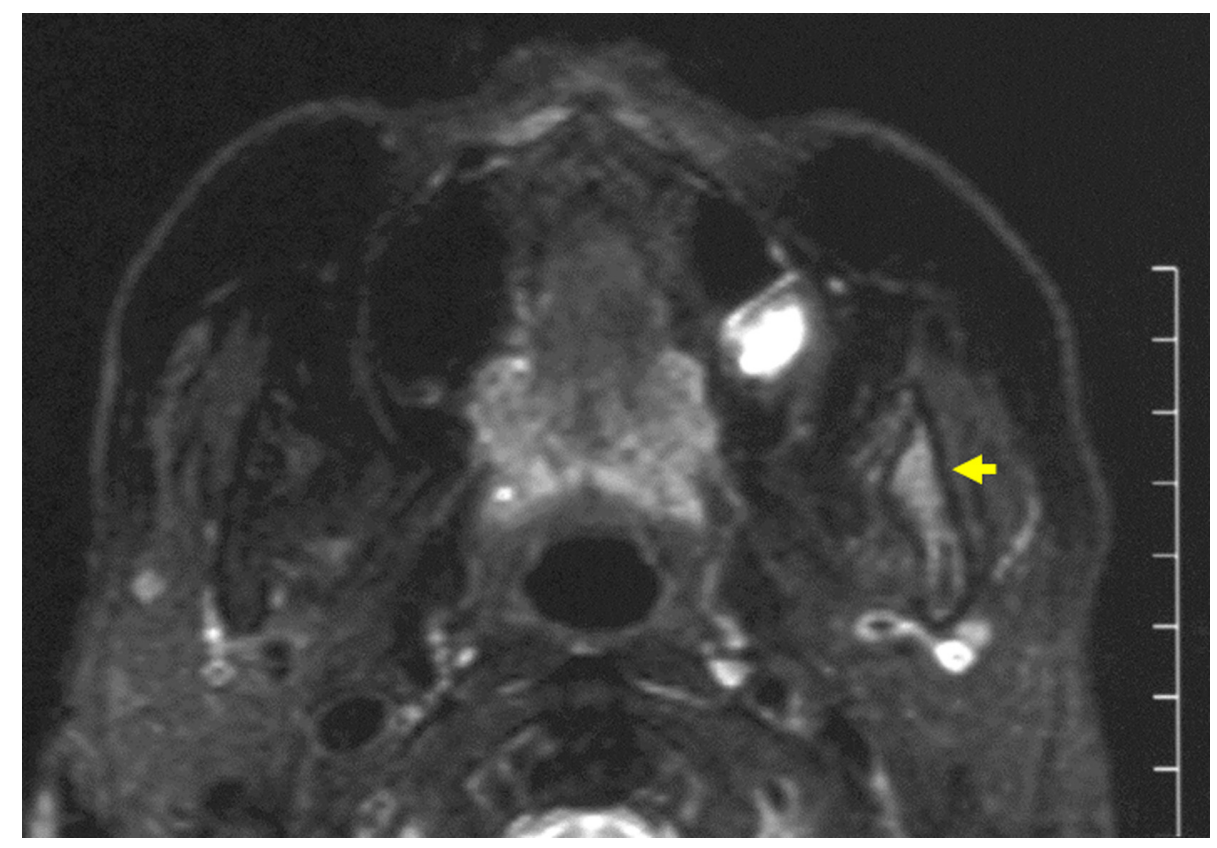

Figure 3 Magnetic resonance imaging at first visit.

Note: The left side of the ascending ramus of the mandible shows heterogeneous intermediate-to-high signal intensity on fat-suppressed $\mathrm{T}_{2}$-weighted images. 


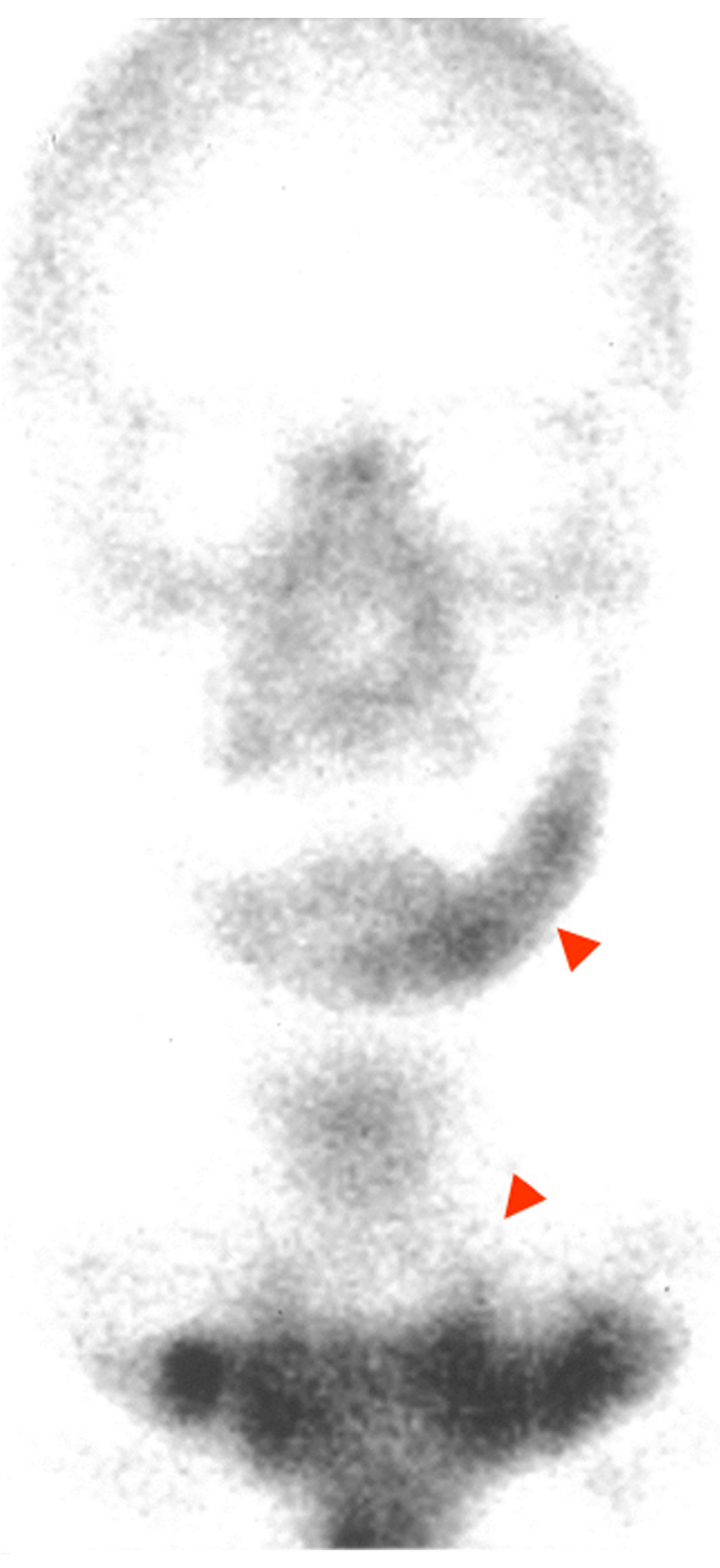

Figure 4 Bone scintigram ( ${ }^{99 \mathrm{~m}} \mathrm{Tc}$-labeled methylene diphosphonate) at first visit, showing extremely intense tracer uptake in the left side of the mandible, the sternum, and the sternocostal and sternoclavicular joints.

It is presumed that the osteitis and skin lesions seen in SAPHO syndrome are the results of sustained but lowgrade infection with anerobic microorganisms such as Propionibacterium acnes odontogenic focal infection, ${ }^{16}$ which persist in the osteitis lesions in a form that is incompatible with culturing, but triggers a nonspecific activation/ dysfunction of innate and T-cell-mediated immune responses in genetically predisposed individuals. ${ }^{14}$

It has been suggested that SAPHO syndrome represents hyperstimulation of the innate immune response in these

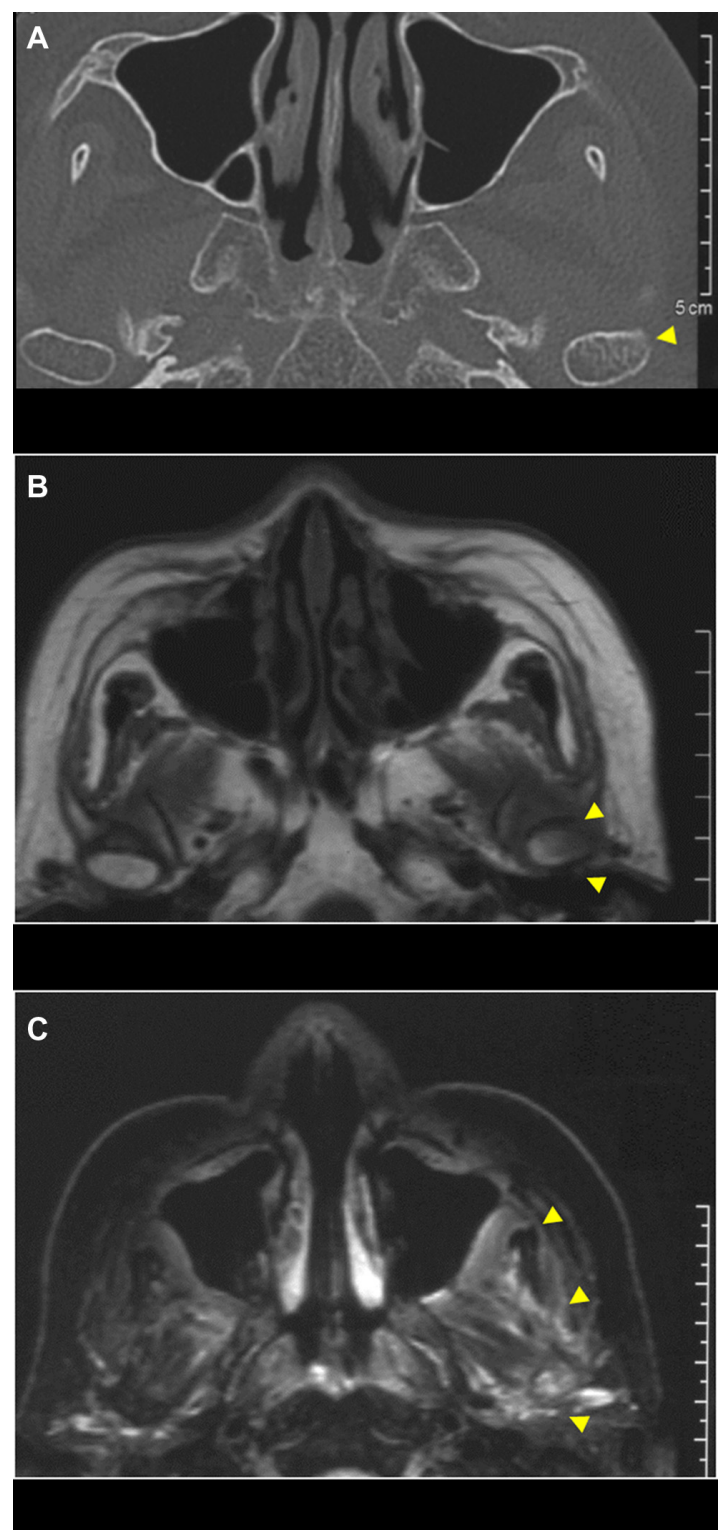

Figure $5 \mathrm{CT}$ and $\mathrm{MRI}$ at 4-month follow-up after the first visit: (A) plain CT showing diffuse cortical bone resorption of the left condyle of the mandible; (B) MRI, with the left condyle of the mandible in part showing low-high signal intensity on a $\mathrm{T}_{\text {1 }}$-weighted image; (C) MRI, with soft tissue around the left side of the ascending ramus of the mandible showing heterogeneous high-signal intensity on a fatsuppressed $\mathrm{T}_{2}$-weighted image.

Abbreviations: CT, computed tomography; MRI, magnetic resonance imaging.

disorders, as reflected by increased production of interleukin-8 and tumor necrosis factor- $\alpha .{ }^{16}$ It has also been suggested that a possible genetic abnormality with a pathogenic role might be characterized by impaired production of an internal oxidant, with subsequent exaggerated inflammatory response causing SAPHO syndrome. ${ }^{17}$ However, this hypothesis is largely unproven. ${ }^{14}$ One report that suggested a chronic apical lesion on a mandibular first molar might be associated with the occurrence of SAPHO syndrome. ${ }^{18}$ In this case, the patient had experienced a chronic apical lesion of the mandibular left canine 


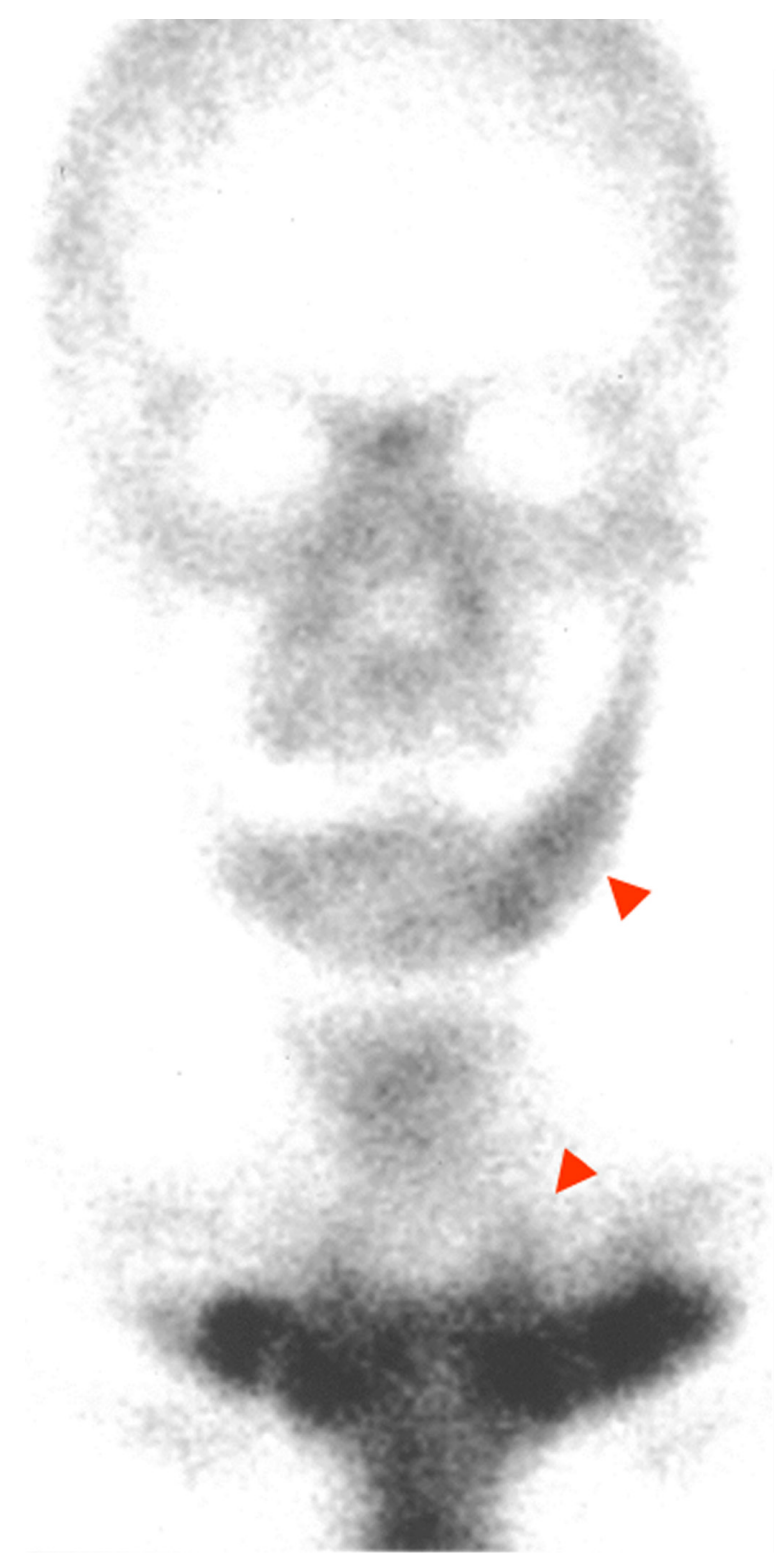

Figure 6 Bone scintigram 6 months after administration of antibiotics.

Note: Radioisotope uptake in the left mandible is unchanged, while radioisotope uptake in the sternum and in the sternocostal and sternoclavicular joints is increased, compared with the images of the first visit.

before diagnosis of mandibular osteomyelitis. Dental foci could serve as the origin of the mandibular osteomyelitis and osteitis of the sternum and sternocostal and sternoclavicular joints.

\section{Diagnosis of SAPHO syndrome}

The distinct clinical features of SAPHO syndrome are skin and osteoarticular manifestations. The skin manifestations may precede or follow the bone lesions, usually by years but in some cases more than a decade. ${ }^{3,4,19}$ Diagnosis of SAPHO can be difficult in the absence of skin lesions or involvement with only one symptomatic bone site. ${ }^{20}$
When SAPHO syndrome is suspected or diagnosed, the patient should undergo systemic whole-body technetium scintigraphy to exclude other asymptomatic lesions. In this case, we could not have found the asymptomatic osteitis of the sternum and sternocostal and sternoclavicular joints before bone scintigram.

Suei et $\mathrm{al}^{9}$ suggest that the original site of osteomyelitis in SAPHO syndrome is not bone but periosteum. Proinflammatory cytokines such as interleukin-8 and tumor necrosis factor- $\alpha$ are produced in the inflamed periosteum and stimulate osteoblasts and osteoclasts by promoting periosteal bone formation in addition to cortical bone resorption. They suggest that radiographic findings vary in osteomyelitis associated with SAPHO syndrome. ${ }^{9}$ Mixed patterns with initial osteolyses and diffuse sclerosis, bone enlargement with extensive cortical bone resorption, and solid periosteal reaction have been reported frequently in osteomyelitis of SAPHO syndrome. ${ }^{9,21}$ Our case constituted diffuse cortical bone resorption of the left condyle of the mandible and reactive sclerosis of the subcondylar bone. Routine blood tests reveal elevated acute phase reactants, such as C-reactive protein, erythrocyte sedimentation rate, and elevated levels of complements $\mathrm{C} 3$ and $\mathrm{C} 4$, as seen in our case. ${ }^{14}$ Zhao et $\mathrm{al}^{22}$ reported that a moderately increased leukocyte count, mild anemia and an elevated erythrocyte sedimentation, and elevated level of immunoglobulin A were observed.

\section{Treatment}

The treatment of SAPHO syndrome is empirical and based on anecdotal experiences or small control studies. ${ }^{23}$ There are currently no guidelines, so the treatment for SAPHO syndrome has focused mainly only on symptoms and complaints, such as bone pain and tenderness. ${ }^{24}$ Conservative treatment, such as with drugs and/or hyperbaric oxygen, is recommended as a first-line therapy.

\section{Drugs}

Based on the assumption that $P$. acnes is involved in the pathogenesis of SAPHO syndrome, antibiotic therapy and NSAIDs have been used to treat SAPHO syndrome, with varying success. ${ }^{15}$ It has also been reported that clindamycin and tetracycline were effective. ${ }^{7,25,26}$ According to some recent reports, macrolides or new quinolones effectively inhibit the production of various inflammatory cytokines, such as interleukin-1, $-6,-8$, and tumor necrosis factor- $\alpha .{ }^{27,28}$ For a drug combination, Schilling ${ }^{29}$ recommended azithromycin, which has both anti-inflammatory and immunomodulating 
activity, and calcitonin, which is a hormonal osteotropic drug. However, we could not detect previous reports of effectiveness of combination of macrolides and new quinolones, as we used in this case. The effectiveness of our combined regimens should be further studied. Some studies have reported the effectiveness of corticosteroids or bisphosphonates for SAPHO syndrome. ${ }^{29,30}$ Because these drugs have systemic pharmacological functions and serious side effects, oral surgeons should consult closely with other physicians in the use of these medications. ${ }^{30}$ The decision of when to stop administration of drugs seems to depend on each patient's degree of improvement of clinical symptoms, such as pain, range of trismus, and radiographic findings. In the absence of additional osteolytic change in bone lesions, along with the resolution of symptoms, treatment may be presumed effective for chronic mandibular diffuse sclerosing osteomyelitis, even if osteosclerosis remains unchanged. ${ }^{27}$

\section{Surgery}

The recurrence rate after decortication treatment or partial resection of the affected bone is reported to be high. ${ }^{30-32}$ Roldán et $\mathrm{al}^{26}$ reported a case of SAPHO syndrome with ineffective decortications; therefore, surgical intervention is not recommended. ${ }^{33}$ Wide resection of the affected mandibular bone and immediate reconstruction using microvascular flaps seems to be recommended only if a patient experiences deformity, loss of function, increasing pain, and failure of conservative treatments. ${ }^{10}$ The bone donor site for mandibular reconstruction in a SAPHO patient could also be affected by osteomyelitis. Long bones are affected by SAPHO syndrome in $30 \%$ of cases, ${ }^{1}$ mostly involving the femur and the tibia. ${ }^{34}$ In $10 \%$ of cases, the ilium is affected. Involvement of the donor site should be excluded by ${ }^{99 \mathrm{~m}}$ Tc-labeled methylene diphosphonate scintigraphy and strictly followed up according to future involvement of the transplanted bone.

\section{Prognosis}

SAPHO syndrome is chronic, with frequent remissions and exacerbations. It has been reported that cases of chronic mandibular diffuse sclerosing osteomyelitis that have extended to the ascending ramus of the mandible tend to take longer for resolution of symptoms ${ }^{27}$ and have a higher rate of recurrence. ${ }^{35}$ In our case, although there has been no pain or swelling in the area of the left mandibular lesion, we have followed up to prevent lesions from developing other skin or osteoarticular manifestations.

SAPHO syndrome may be occasionally confused with malignancy or infection, and some patients may undergo unnecessary invasive procedures. ${ }^{20,36} \mathrm{~A}$ high index of clinical suspicion of SAPHO syndrome is necessary for accurate diagnosis. ${ }^{20}$ Oral surgeons must consult with physicians in such specialties as dermatology, orthopedics, and internal medicine when SAPHO syndrome is suspected.

\section{Conclusion}

Although this report is based on a single case, it provides information on one of the treatments - specifically, the combination of macrolides or new quinolones and bisphosphonates - for intractable chronic mandibular osteomyelitis that was suspected to be SAPHO syndrome.

\section{Acknowledgments}

The authors would like to thank the patient, nurses, and other medical staff.

\section{Disclosure}

The authors report no conflicts of interest in this work.

\section{References}

1. Chamot AM, Benhamou CL, Kahn MF, Beraneck L, Kaplan G, Prost A. Acne-pustulosis-hyperostosis-osteitis syndrome. Results of a national survey. 85 cases. Rev Rhum Mal Osteoartic. 1987;54(3):187-196.

2. Chigira M, Shimizu T. Computed tomographic appearances of sternocostoclavicular hyperostosis. Skeletal Radiol. 1989;18(5): 347-352.

3. Sonozaki H, Azuma A, Okai K, et al. Clinical features of 22 cases with "inter-sterno-costo-clavicular ossification." A new rheumatic syndrome. Arch Orthop Trauma Surg. 1979;95(1-2):13-22.

4. Laasonen LS, Karvonen SL, Reunala TL. Bone disease in adolescents with acne fulminans and severe cystic acne: radiologic and scintigraphic findings. AJR Am J Roentgenol. 1994;162(5):1161-1165.

5. Sonozaki H, Mitsui H, Miyanaga Y, et al. Clinical features of 53 cases with pustulotic arthro-osteitis. Ann Rheum Dis. 1981;40(6):547-553.

6. Hayem G, Bouchaud-Chabot A, Benali K, et al. SAPHO syndrome: a long-term follow-up study of 120 cases. Semin Arthritis Rheum. 1999;29(3):159-171.

7. Müller-Richter UDA, Roldan JC, Mörtl M, Behr M, Reichert TE, Driemel O. SAPHO syndrome with ankylosis of the temporomandibular joint. Int J Oral Maxillofac Surg. 2009;38(12):1335-1341.

8. Earwalker JW, Cotton CA. SAPHO: syndrome or concept? Imaging findings. Skeletal Radiol. 2003;32(6):311-327.

9. Suei Y, Taguchi A, Tanimoto K. Diagnosis and classification of mandibular osteomyelitis. Oral Surg Oral Med Oral Pathol Oral Radiol Endod. 2005;100(2):207-214.

10. Zemann W, Pau M, Feichtinger M, Ferra-Matschy B, Kaercher H. SAPHO syndrome with affection of the mandible: diagnosis, treatment, and review of literature. Oral Surg Oral Med Oral Pathol Oral Radiol Endod. 2011;111(2):190-195.

11. Kahn MF, Khan MA. The SAPHO syndrome. Baillieres Clin Rheumatol. 1994;8(2):333-362.

12. Hukuda S, Minami M, Saito T, et al. Spondyloarthropathies in Japan: nationwide questionnaire survey performed by the Japan Ankylosing Spondylitis Society. J Rheumatol. 2001;28(3):554-549.

13. Yabe H, Ohshima H, Takano Y, et al. Mucosal lesions may be a minor complication of SAPHO syndrome: a study of 11 Japanese patients with SAPHO syndrome. Rheumatol Int. 2010;30(10):1277-1283. 
14. Colina M, Govoni M, Orzincolo C, Trotta F. Clinical and radiologic evolution of synovitis, acne, pustulosis, hyperostosis, and osteitis syndrome: a single center study of a cohort of 71 subjects. Arthritis Care Res. 2009;61(6):813-821.

15. Magrey M, Khan MA. New insights into synovitis, acne, pustulosis, hyperostosis, and osteitis (SAPHO) syndrome. Curr Rheumatol Rep. 2009;11(5):329-333.

16. Hurtado-Nedelec M, Chollet-Martin S, Nicaise-Roland P, et al. Characterization of the immune response in the synovitis, acne, pustulosis, hyperostosis, osteitis (SAPHO) syndrome. Rheumatology (Oxford). 2008;47(8):1160-1167.

17. Ferguson PJ, Lokuta MA, El-Shanti HI, Muhle L, Bing X, Huttenlocher A. Neutrophil dysfunction in a family with a SAPHO syndrome-like phenotype. Arthritis Rheum. 2008;58(10):3264-3269.

18. Kahn MF, Bouvier M, Palazzo E, Tebib JG, Colson F. Sternoclavicular pustulotic osteitis (SAPHO). 20-year interval between skin and bone lesions. J Rheumatol. 1991;18(7):1104-1108.

19. Yamamoto T, Yamamoto S, Umemura M, Shibata A, Makino S. Chronic mandibular osteomyelitis with suspected relation to palmoplantar pustulosis. Aichi Gakuin Daigaku Shigakkai Shi. 2010;48(2):93-98. Japanese.

20. Karadag-Saygi E, Gunduz OH, Gumrukcu G, Akyuz G. SAPHO syndrome: misdiagnosed and operated. Acta Reumatol Port. 2008;33(4):460-463.

21. Suei Y, Taguchi A, Tanimoto K. Diffuse sclerosing osteomyelitis of the mandible: its characteristics and possible relationship to synovitis, acne, pustulosis, hyperostosis, osteitis (SAPHO) syndrome. J Oral Maxillofac Surg. 1996;54(10):1194-1200.

22. Zhao Z, Li Y, Li Y, Zhao H, Li H. Synovitis, acne, pustulosis, hyperostosis and osteitis (SAPHO) syndrome with review of the relevant published work. J Dermatol. 2011;38(2):155-159.

23. Olivieri I, Padula A, Palazzi C. Pharmacological management of SAPHO syndrome. Expert Opin Investig Drugs. 2006;15(10):1229-1233.

24. Yanamoto S, Kawasaki G, Yoshitomi I, Mizuno A. Diffuse chronic sclerosing osteomyelitis of the mandible with synovitis, acne, pustulosis, hyperostosis, and osteitis: report of a long-term follow-up case. J Oral Maxillofac Surg. 2010;68(1):212-217.

25. Utumi ER, Oliveira Sales MA, Shinohara EH, et al. SAPHO syndrome with temporomandibular joint ankylosis: clinical, radiological, histopathological, and therapeutical correlations. Oral Surg Oral Med Oral Pathol Oral Radiol Endod. 2008;105(3):e67-e72.
26. Roldán JC, Terheyden H, Dunsche A, Kampen WU, Schroeder JO. Acne with chronic recurrent multifocal osteomyelitis involving the mandible as part of the SAPHO syndrome: case report. Br J Oral Maxillofac Surg. 2001;39(2):141-144.

27. Yoshii T, Nishimura H, Yoshikawa T, et al. Therapeutic possibilities of long-term roxithromycin treatment for chronic diffuse sclerosing osteomyelitis of the mandible. J Antimicrob Chemother. 2001;47(5):631-637.

28. Tsuda T, Ishikawa C, Konishi H, et al. Effect of 14-membered-ring macrolides on production of interleukin- 8 mediated by proteaseactivated receptor 2 in human keratinocytes. J Antimicrob Chemother. 2008;52(4):1538-1541.

29. Schilling F. SAPHO syndrome. Orphanet Encyclopaedia [serial on the Internet]. 2004 Oct. Available from: http://www.orpha.net/data/patho/ GB/uk-SAPHO.pdf. Accessed February 17, 2009.

30. Hatano H, Shigeishi H, Higashikawa K, et al. A case of SAPHO syndrome with diffuse sclerosing osteomyelitis of the mandible treated successfully with prednisolone and bisphosphonate. J Oral Maxillofac Surg. August 2, 2011. [Epub ahead of print.]

31. Jurik AG, Moller BN. Chronic sclerosing osteomyelitis of the clavicle. a manifestation of chronic recurrent multifocal osteomyelitis. Arch Orthop Trauma Surg. 1987;106(3):144-151.

32. Montonen M, Iizuka T, Hallikainen D, Lindqvist C. Decortication in the treatment of diffuse sclerosing osteomyelitis of the mandible. Retrospective analysis of 41 cases between 1969 and 1990. Oral Surg Oral Med Oral Pathol. 1993;75(1):5-11.

33. Eyrich GKH, Harder C, Sailer HF, Langenegger T, Bruder E, Michel BA. Primary chronic osteomyelitis associated with synovitis, acne, pustulosis, hyperostosis and osteitis (SAPHO syndrome). J Oral Pathol Med. 1999;28(10):456-464.

34. Mylona E, Golfinopoulou S, Peppas C, Fanourgiakis P, Skoutelis A. Femoral and lower costosternal junctions' osteitis in an adult with SAPHO syndrome: an unusual presentation. Joint Bone Spine. 2008; 75(3):338-340.

35. Jacobsson S. Diffuse sclerosing osteomyelitis of the mandible. Int $J$ Oral Surg. 1984;13(5):363-385.

36. Van Doornum S, Barraclough D, McColl G, Wicks I. SAPHO: rare or just not recognized? Semin Arthritis Rheum. 2000;30(1):70-77.
Journal of Inflammation Research

\section{Publish your work in this journal}

The Journal of Inflammation Research is an international, peer-reviewed open-access journal that welcomes laboratory and clinical findings on the molecular basis, cell biology and pharmacology of inflammation including original research, reviews, symposium reports, hypothesis formation and commentaries on: acute/chronic inflammation; mediators of inflamma-

\section{Dovepress}

tion; cellular processes; molecular mechanisms; pharmacology and novel anti-inflammatory drugs; clinical conditions involving inflammation. The manuscript management system is completely online and includes a very quick and fair peer-review system. Visit http://www.dovepress.com/ testimonials.php to read real quotes from published authors. 